\title{
Australian magnetic field effects during geomagnetic storms
}

\author{
W. H. Campbell ${ }^{1}$, C. E. Barton ${ }^{2}$, P. Hopgood ${ }^{2}$, and D. G. Cole ${ }^{3}$ \\ ${ }^{1}$ National Geophysical Data Center, NOAA, USA \\ ${ }^{2}$ Geoscience Australia, Australia \\ ${ }^{3}$ IPS Radio and Space Services of Australia, Australia
}

(Received September 24, 2002; Revised October 8, 2003; Accepted October 8, 2003)

\begin{abstract}
Using Australian records, we studied six isolated geomagnetic storms for the regional effects of their associated magnetic fields, emphasizing the linear regression correlation coefficient between station locations and indices. An innovation used here was to consider both the full magnetic disturbance field and a form of this field with the smoothed storm-time Dst values removed to feature the small variations. Magnetic H-component data from paired stations throughout the continent showed correlation values of +0.90 to +0.97 . These results indicate the adequacy of the present density of observatories in Australia and their value for use with aeromagnetic surveys. The planetary magnetic ap index was found to have an inconsistent relationship to Australian H-component fields. The planetary magnetic Dst index was successfully represented by data from four Australian observatories. The discovered capability of Australian magnetic observatories to represent the magnetic storm Dst index in real time, combined with the established lognormal-form characteristic of Dst, means that Australian solar-terrestrial disturbance centers should be able to predict the time to recovery of quieter fields once an on-line Austrialian magnetic field Dst mainphase computation has been made.
\end{abstract}

Key words: Geomagnetism, magnetic storms, Dst index.

\section{Introduction}

For this presentation, the expression "Geomagnetic Storms" will be used in the general sense to embrace the response of fields and particles near the Earth resulting from disturbances originating at the Sun and brought to the Earth's magnetosphere by the solar wind. During geomagnetic storms the records of both the magnetic fields and ionospheric conditions become quite disturbed from the levels expected at the non-storm "quiet time" periods. This present study is limited to geomagnetic storms in Australia to be seen as the behavior of observatory-measured values of the horizontal $(\mathrm{H})$ components of the magnetic fields.

\subsection{Background and Objectives}

Long ago Moos (1910) brought attention to the similar pattern of field disturbances that we now identify as global magnetic storms. Since that time, numerous textbooks have detailed the storm field characteristics and related activity indices (cf. most recently, Jacobs (1991) and Campbell (2001, 2003)). There are two objectives for the present study of magnetic data. The first is to understand how extensively the features of storm-time disturbance fields are distributed over the great expanse of the Australian continent in order to evaluate the adequacy of the present number of stations in representing the continental field behavior for an aeromagnetic survey program. The second objective is to determine how well the local fields relate to international magnetic disturbance indices and if Australian proxies for such indices can be determined in order to overcome the usual delay in

Copy right(C) The Society of Geomagnetism and Earth, Planetary and Space Science (SGEPSS); The Seismological Society of Japan; The Volcanological Society of Japan; The Geodetic Society of Japan; The Japanese Society for Planetary Sciences. obtaining indices from international centers.

The Dst index (prepared at Kyoto University) is an hourly index representative of the average $\mathrm{H}$-component of field (with an estimated quiet-day field values removed) from 4 (or sometimes 5) low-latitude magnetic observatories (usually Kakioka, Honolulu, San Juan, and Hermanus) for which an adjustment has been made with a division by the cosine of the average geomagnetic latitude of the contributing stations (Campbell, 2003). When the Dst index was originally codified (Sugiura, 1964) it was believed that the magnetic storm could be represented by the growth and decay of a simple ring current in the Van Allen belt surrounding the Earth. However, subsequent definitive research discounted that model (cf. Section News, "Dst is not a Pure RingCurrent Index", EOS, July 28, 1996) in favor of a composite of many partial ring currents that feed field-line-guided currents of particles to and from the auroral regions and cause the flow of disturbance currents in the ionosphere. The index is still a valuable indicator of global storms.

It has been demonstrated (Campbell, 1996) that the lognormal form of the Dst index can be transformed to a normal distribution such that the recovery phase of the storm can be obtained from the storm's main phase. With the information that a real-time Australian station proxy for the magnetic Dst index can be obtained, then the prediction of the time of recovery of a storm disturbance period is realizable for the Australian solar-terrestrial distubance forecasting centers.

\subsection{Analysis Procedure}

Our study uses magnetic data gathered by the Geomagnetism Group of Geoscience Australia in 1990 when their standard observatories were supplemented with a longitude chain of stations through central Australia (called the 


\section{Location of Magnetic Stations}

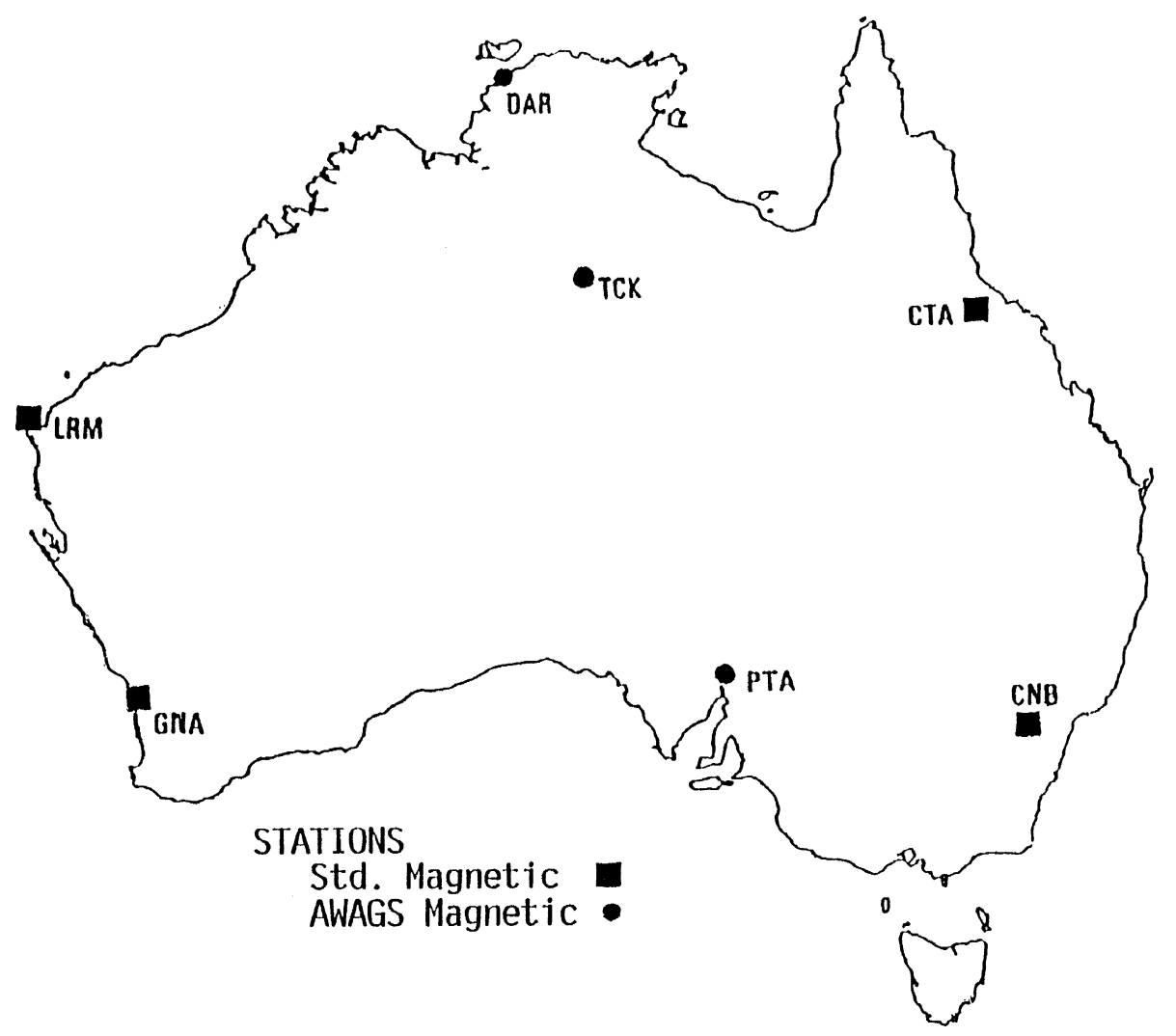

Fig. 1. Map of Australian observatories listed in Table 1.

Table 1. Location of Australian magnetic stations used for this study.

\begin{tabular}{ccccl}
\hline \multicolumn{6}{c}{ Standard Magnetic Stations } \\
Sta & Lat & Long & gmLat & Name \\
\hline CTA & -20.09 & 146.25 & -28.52 & Charters Towers \\
LRM & -22.22 & 114.10 & -33.02 & Learmonth \\
GNA & -31.78 & 115.95 & -42.54 & Gnangara \\
CNB & -35.32 & 149.36 & -43.20 & Canberra \\
\hline \multicolumn{7}{l}{ AWAGS Temporary Magnetic Stations } \\
Sta & Lat & Long & gmLat & Name \\
\hline DAR & -12.42 & 130.87 & -22.40 & Darwin \\
TCK & -19.63 & 134.18 & -29.35 & Tennant Creek \\
PTA & -32.48 & 137.75 & -41.79 & Pt. Augusta \\
\hline
\end{tabular}

AWAGS set). Figure 1 and Table 1 illustrate the locations of these observatories. The mid-latitude magnetic stations extended through a range of about 23 degrees in south latitude and 35 degrees in longitude.

Figure 2 shows an example of two geomagnetic activity indices, ap (a linear field form of $\mathrm{Kp}$, the pseudo-logarithmic index) and Dst (a storm-time disturbance index), that are both readily available from World Data Center A (http: //www.ngdc.noaa.gov). A classical magnetic storm was defined by Chapman (1951) as having an initial phase, main phase, and recovery phase as displayed in Fig. 2 by the Dst index. In addition, often the exact time of a "sudden com-
Table 2. As determined by the published Dst indices, the following selected starting dates, durations, and hour of main phase start for the isolated geomagnetic storms in 1990 were preceded by relatively quiet times and showed a full recovery period.

\begin{tabular}{cccccc}
\hline Day\# & Day & Month & Year & Days & UT (hr) \\
\hline 107 & 17 & Apr & 1990 & 3 & 9 \\
209 & 28 & Jul & 1990 & 3 & 9 \\
238 & 26 & Aug & 1990 & 3 & 8 \\
282 & 9 & Oct & 1990 & 3 & 18 \\
331 & 27 & Nov & 1990 & 3 & 15 \\
346 & 12 & Dec & 1990 & 2 & 20 \\
\hline
\end{tabular}

mencement" of the storm can be identified. The storm-time changes of Dst, are published monthly, as hourly values, by the World Data Center for Geomagnetism at Kyoto University. Using these Kyoto Dst tables for global magnetic activity measures, we have limited this study to "isolated storms" in which the Dst records were essentially quiet on the full day before the storm and showed a classical recovery phase. We started with nine isolated storms throughout 1990 but, because of missing data, only six of these were finally available for analysis. These storms (Table 2) are identified by the first U.T. day, the time of the initial phase onset, and the number of days (duration) from then through the recovery phase. 


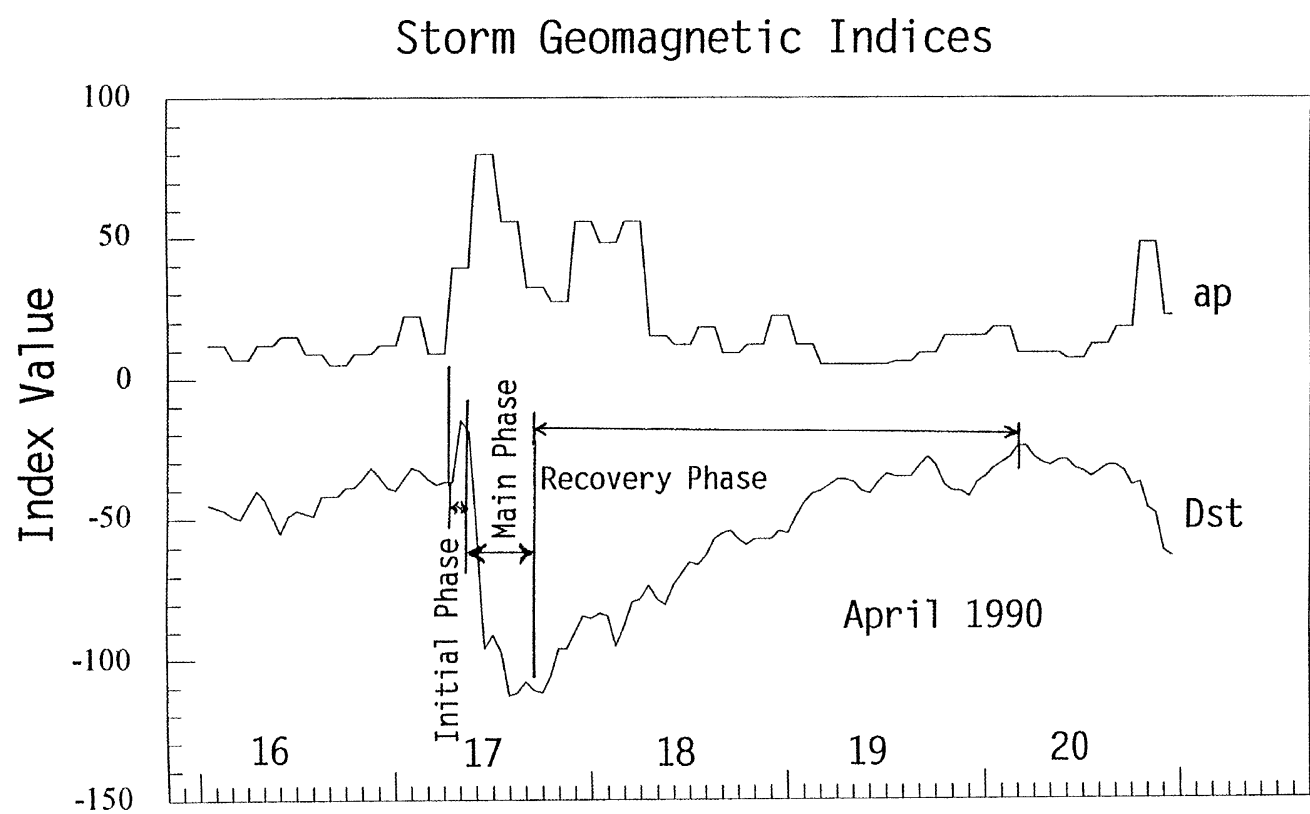

U.T. Day of Month

Fig. 2. Geomagnetic ap and Dst indices with names of the classic Dst divisions for the typical magnetic storm that occurred during the period of 17 to 19 April 1990.

\section{Removal of Quiet Day Sq}

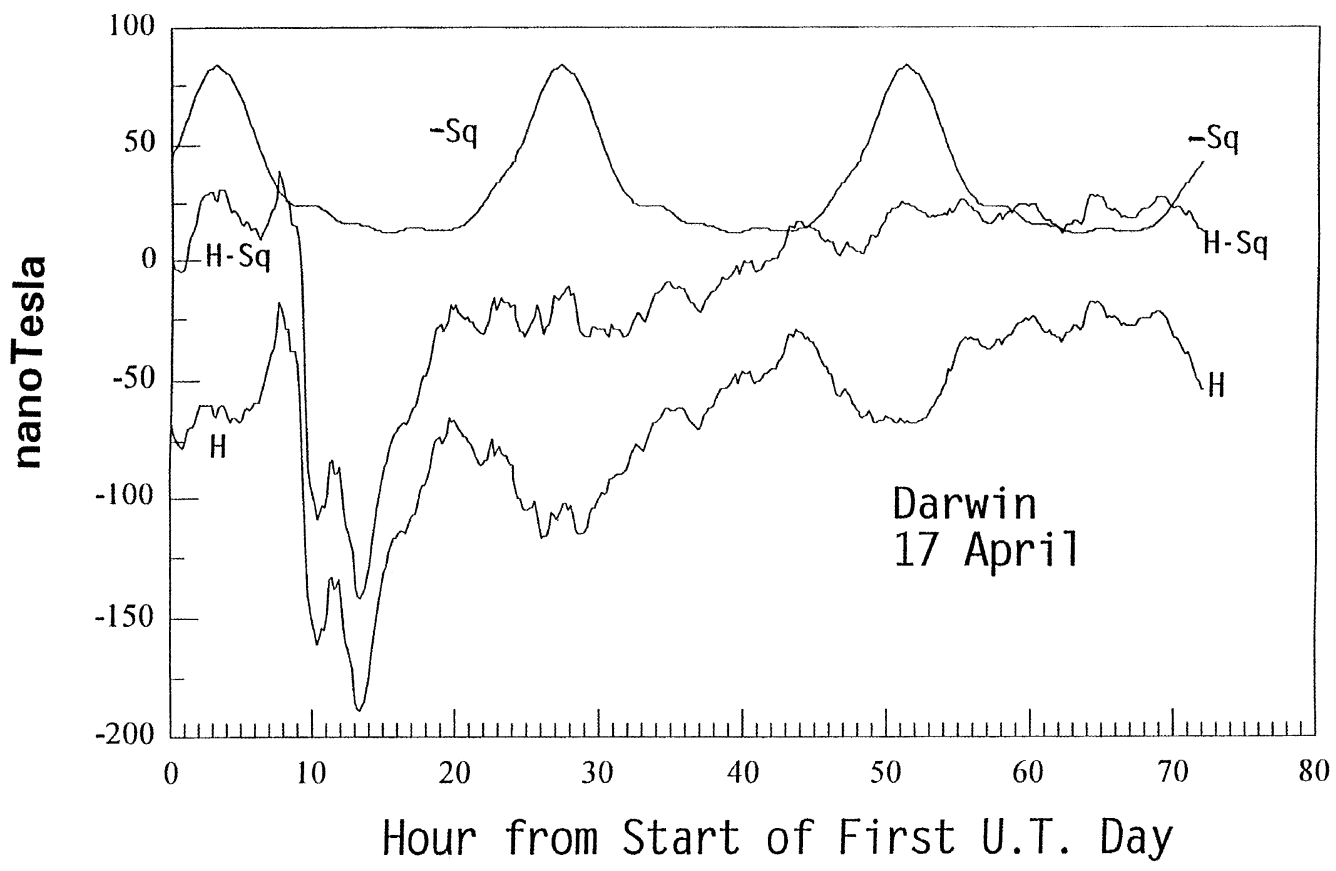

Fig. 3. Shape of solar quiet-time variation $(\mathrm{Sq})$ that is to be removed and the horizontal $(\mathrm{H})$ field component before and after Sq dynamo current removal at the Darwin Magnetic Observatory for the storm starting on 17 April, 1990. Records have been artificially offset for display purposes.

This study will begin with a consideration of the extent of field disturbance similarities in latitude and longitude. We will then compare the Australian magnetic storm records with the ap and Dst magnetic indices. Averages of the shorter data increments are adjusted to match corresponding time intervals of different indices. Throughout this study we will depend on the linear regression correlation coefficients as a measure correspondence for the storm duration (Table 2) and on a timing individual pulses.

\section{Preparation of Magnetic Records}

The Australian magnetic observatories' data were obtained as one-minute full-field values in the geographic northward (x), eastward (y), and into the Earth (z) directions. After finding the local declination (angle eastward to the horizontal main field direction) the equivalent magnetic compo- 

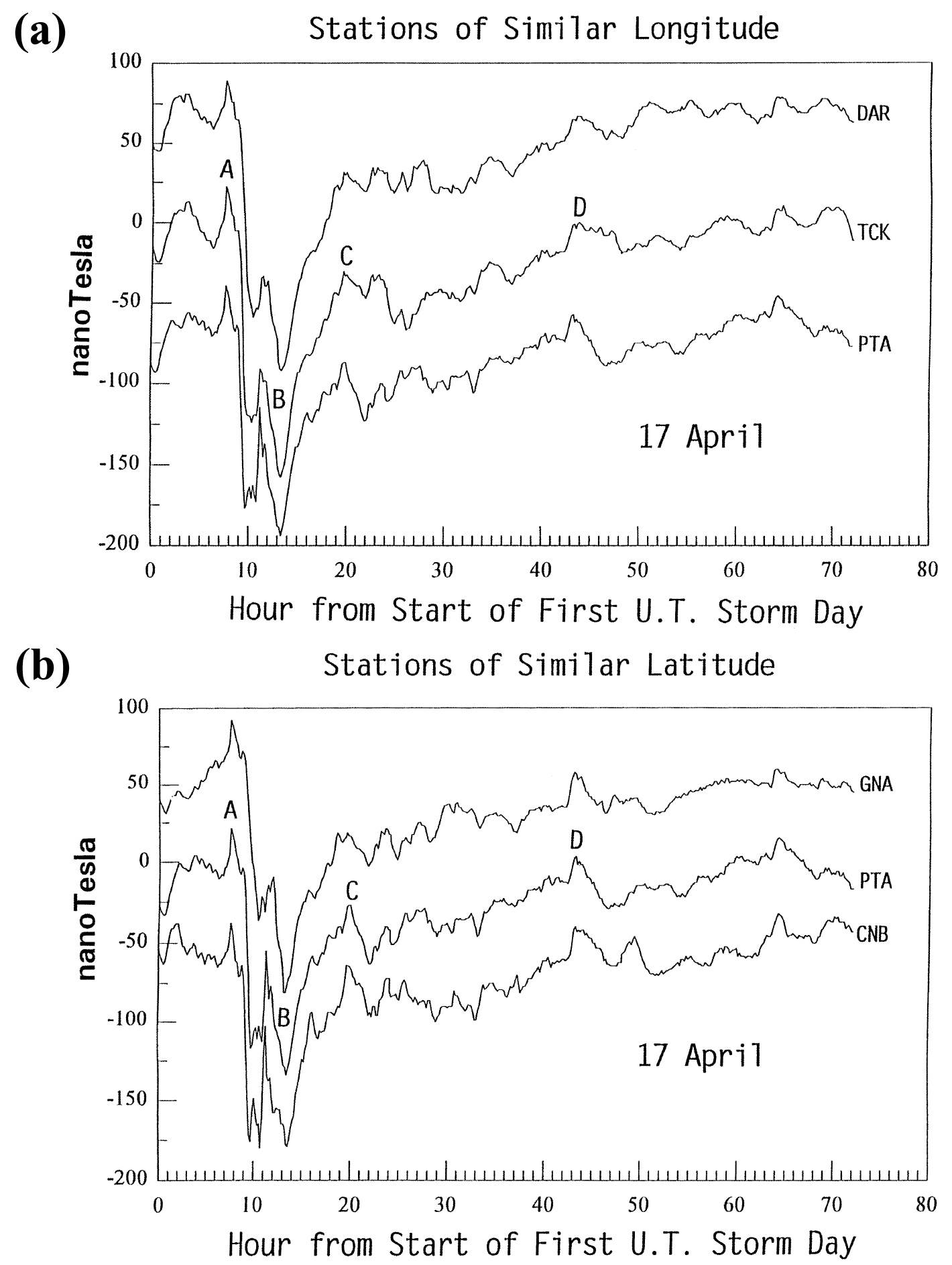

Fig. 4. Fields of the 17 April storm at separated stations with (a) similar longitudes but different latitudes (Darwin, Tennant Creek, and Port Augusta) and (b) similar low latitudes and different longitudes (Gnangara, Port Augusta, and Canberra). Letters A to D indicate field spikes selected for timing.

nents northward $(\mathrm{H})$ and eastward (D) were calculated. Next, with instrumental spikes and step offsets removed from the data, the average 10-minute values of $\mathrm{H}, \mathrm{D}$, and $\mathrm{Z}$, were determined to reduce to quantity of records. Where appropriate for plotting, half-hour values of $\mathrm{H}$ were calculated from the three 10-minute values centered on the half hour.

\section{Removal of Main and Quiet-Variation Fields}

The H-component field measurements during the selected storm days are divided into three parts: the main field, the quiet-time (Sq) daily variation field, and the disturbance field. The present study concerns the disturbance field only. The main and Sq fields need be removed for our study. The largest of these, the baseline main, dipole-like, field of the Earth changes quite slowly over the years (secular variation) and shows only the small seasonal distortion of the magnetosphere. Our storms had been selected for their sudden onset following a day of quiet behavior. Thus, to represent a consistent baseline level, it was found sufficient to use the value from an hour's average of the reported 10-min field levels 
Table 3. Average of the linear regression correlation coefficients for the magnetic field levels of listed paired stations during the six storms.

\begin{tabular}{|c|c|c|c|c|c|c|}
\hline \multicolumn{7}{|c|}{ (a) All storm-time values } \\
\hline & TCK & PTA & CTA & LRM & GNA & $\mathrm{CNB}$ \\
\hline DAR & 0.98 & 0.94 & 0.97 & 0.96 & 0.92 & 0.92 \\
\hline TCK & & 0.95 & 0.98 & 0.97 & 0.92 & 0.93 \\
\hline PTA & & & 0.93 & 0.95 & 0.94 & 0.97 \\
\hline CTA & & & & 0.94 & 0.90 & 0.92 \\
\hline LRM & & & & & 0.95 & 0.93 \\
\hline GNA & & & & & & 0.92 \\
\hline \multicolumn{7}{|c|}{ (b) Storms with lognormal Dst removed } \\
\hline & TCK & PTA & CTA & LRM & GNA & $\mathrm{CNB}$ \\
\hline DAR & 0.92 & 0.83 & 0.92 & 0.90 & 0.75 & 0.80 \\
\hline TCK & & 0.87 & 0.96 & 0.94 & 0.78 & 0.85 \\
\hline PTA & & & 0.82 & 0.85 & 0.86 & 0.89 \\
\hline CTA & & & & 0.86 & 0.74 & 0.83 \\
\hline LRM & & & & & 0.86 & 0.83 \\
\hline GNA & & & & & & 0.81 \\
\hline
\end{tabular}

centered on the predawn 4 am local time at each observatory for the quiet day preceding the selected storm. This field level was subtracted from each of the storm records on the subsequent 2 to 3 storm days.

The yearly Sq variation on the quietest of days over the Australian region was obtained from the program for recreating the 1990 quiet daily variations as described in Campbell et al. (1998). However, on days of magnetic storms, the conductivity of the ionosphere changes from its quiet level, altering the dynamo Sq currents from their typical quiet-time behavior. Therefore, for each storm field at each station the size of the quiet-day Sq (obtained with the above program) was adjusted by a fixed amplitude until a visual inspection indicated the best removal of the dynamo current Sq from the $\mathrm{H}$ component of the main and recovery phases of the storm (Fig. 3).

\section{Storm Field Variation with Location}

Figures 4(a) and 4(b) illustrate the similarity of storm behavior for stations at the extreme difference in latitudes and longitudes. The longitude spread from Gnangara to Canberra is about $34^{\circ}$ (about $3030 \mathrm{~km}$ ). The latitude spread from Darwin to Port Augusta is about $20^{\circ}$ (about $2960 \mathrm{~km}$ ). To quantify the similarity of the storm fields across Australia, linear regression correlation coefficients were determined between stations for the field-level samples for each storm. As might be suspected there was a high linear regression correlation coefficient between 10-min average field activity at all stations. Table 3(a) shows the average of these correlation storm-time coefficients for the storms of this study; all were positive values. Pairs of stations which were closest showed correlations greater than 0.97 ; stations most widely separated had correlations between 0.90 to 0.93 values.

The storm that started on 17 April had several well-defined activity spikes for which it was possible to determine the simultaneity of the field arrival at the stations by returning to the original 1-minute digital field recordings (AGSO CDROM of AWAGS data, 1996). In Figs. 4(a) and 4(b) the positive spike A occurred at about $7 \mathrm{hr} 33 \mathrm{~min}$ into day 107 , negative spike B occurred about $13 \mathrm{hr} 17 \mathrm{~min}$ into day 107, positive spike C occurred about $19 \mathrm{hr} 41 \mathrm{~min}$ into day 107, and positive spike D occurred about $19 \mathrm{hr} 3 \mathrm{~min}$ into day 108.

For the similar latitude stations (Fig. 4(b)) the large positive spike A maximized at minutes $451-454$ for GNA, at minutes 452-453 for PTA, and at minutes 451-454 for CNB. For the similar longitude stations (Fig. 4(a)) the positive spike A maximized at minute 453 for DAR, at minutes $452-$ 453 for TCK, and at minutes $452-453$ for PTA. There was no measurable difference in the arrival times for this event at all these stations.

For the similar latitude stations, the negative spike B minimized at minutes 796-797 for GNA, at minutes 797-802 for PTA, and at minutes $805-807$ for CNB. For the similar longitude stations the negative spike $\mathbf{B}$ minimized at minutes minute 798 for DAR, at minutes 797-799 for TCK, and at minutes $797-802$ for PTA. The difference in time could indicate that the negative spike had an apparent west-east travel velocity of about $5 \mathrm{~km} / \mathrm{sec}$ and no resolvable north-south difference in arrival time.

For the similar latitude stations, the small positive spike C maximized at minute 1182 for GNA, at minutes 11791181 for PTA, and at minutes 1178-1179 for CNB. For the similar longitude stations, the positive spike $\mathbf{C}$ maximized at minute 1182-1191 for DAR, at minutes 1180 and 1186 for TCK, and at minutes $1179-1181$ and $1185-1188$ for PTA. The difference in time could indicate that the small positive spike had an apparent east-west travel velocity near 13 to $17 \mathrm{~km} / \mathrm{sec}$ and no resolvable north-south difference in arrival time.

For the similar latitude stations, the small positive spike of D maximized at minutes 1140 and 1144 minutes for GNA, at 1142-1145 and 1146-1149 minutes for PTA, and at minutes 1143 and 1146 at CNB. For similar longitude stations, the positive spike D maximized at minutes 1143 and 1146-1149 at DAR, at minutes 1143-1146, 1147, and 1149 at TCK, 


\section{Dst and ap Indices at Time of Storm}

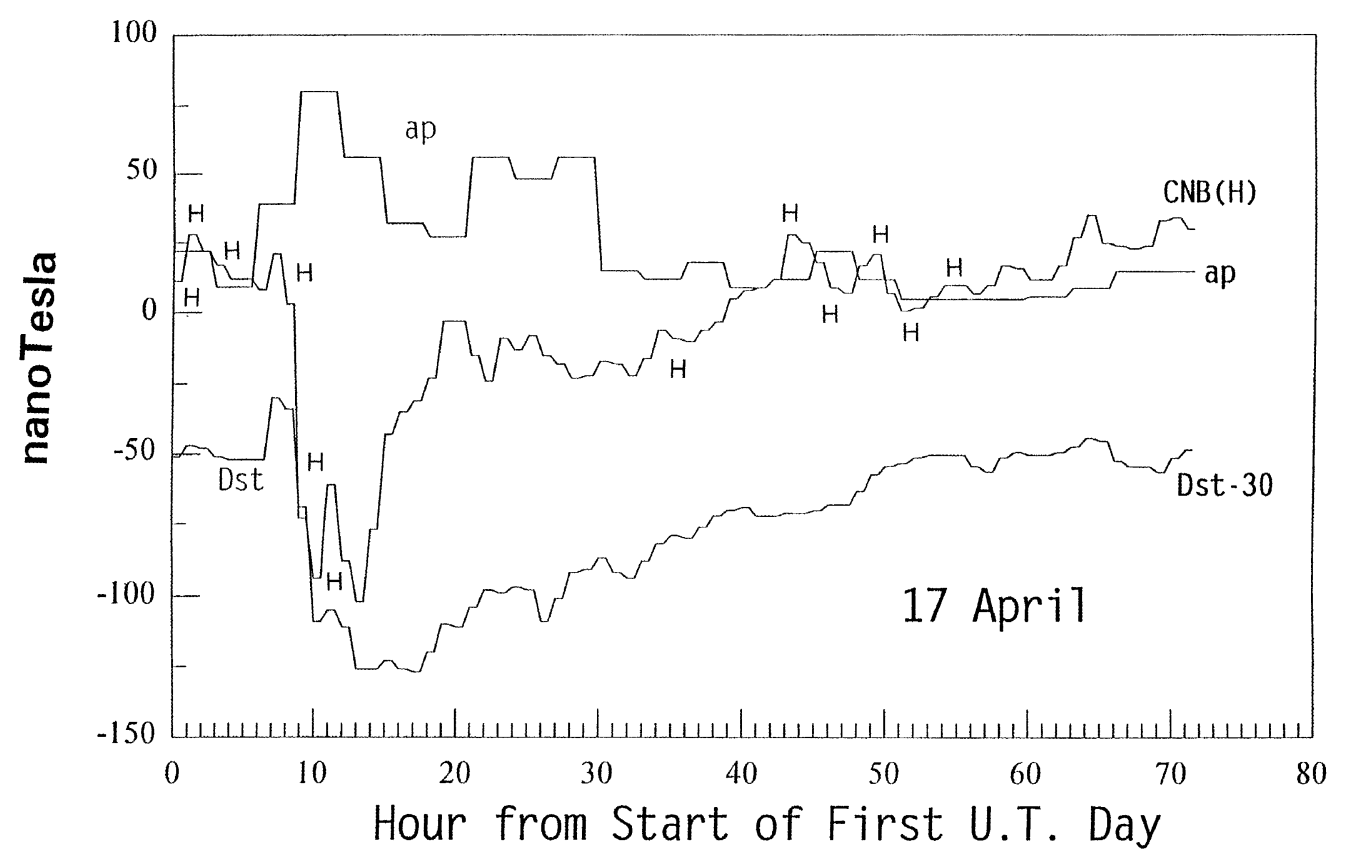

Fig. 5. Hourly Dst and 3-hour ap magnetic indices compared to the half-hour H component of field at Canberra (CNB) for the 17 April storm. Dst is offset -30 for display purposes.

Table 4. Median and average, of the correlations between ap index and the station fields.

\begin{tabular}{|c|c|c|c|c|c|c|}
\hline & 17APR & $28 \mathrm{JUL}$ & 26AUG & 09OCT & $27 \mathrm{NOV}$ & 12DEC \\
\hline Median & -0.74 & -0.40 & -0.75 & -0.68 & -0.13 & -0.23 \\
\hline Av. Correl. & -0.72 & -0.39 & -0.75 & -0.65 & -0.10 & -0.34 \\
\hline
\end{tabular}

and at minutes $1142-1145$ and $1146-1149$ at PTA. This difference in time could indicate that the small positive spike had an apparent west-east travel velocity near $17 \mathrm{~km} / \mathrm{sec}$ and no reasonable north-south difference in arrival time.

\section{Comparisons with the ap Magnetic Index}

The 3-hr Kp, prepared by the University of Goettingen, is said to be the major global index of magnetic activity. This index originates from the range (largest minus smallest level) of the H-component field disturbance in 3-hr (U.T.) time increments for a standard set of global stations. Although the index suffers from its clustered station distribution and 3-hr range sampling, $\mathrm{Kp}$ is considered to be a general picture of global magnetic disturbance level.

To relate the index to our station field levels, the pseudologarithmic form $\mathrm{Kp}$ must be changed to an equivalent field, ap, using a standard conversion table (Campbell, 2003). Fig. 5 compares the ap values with the station field for the 17 April storm. Note that ap, being derived for a field range, is always positive. Table 4 lists the median and averages of the correlation coefficients between the ap index and the station fields for the six storms; all correlation values were negative. (The similarity of median and average values verifies that the average is not overweighted with a few extreme values.) The values of ap have an inconsistent correlation with the local storm activity. Although the ap (from Kp) index does provide information on whether a day can be considered disturbed or not, ap can not be considered a valuable activity index for these Australian storm data.

\section{Comparisons with the Dst Magnetic Index}

Figure 5 is typical of the variation of the indices at times of the storm fields. The correlations between the ap and Dst indices for all storms were always negative and ranged from -0.34 and -0.77 with a median value of -0.63 . Such relationships were similar to the varied correlations between ap and the station field values.

The Dst storm representation has an inverted lognormal shape during the main and recovery storm phases. Magnetic field source contributions (and elements of current causing the fields) are additive, just like the count of the number of statistical events. Lognormal shapes, occurring in nature, result from both the sequential occurrence of normally distributed sources or the simultaneous addition of normally distributed sources (Aitchison and Brown, 1957). A lognormal form is one that can be transformed to its equivalent normal distribution in which the rise to maximum (or fall to minimum) is the mirror image of the subsequent change following the maximum (minimum).

Figure 6 illustrates the fitting of lognormal curves to the six storms of this study. Table 5 shows that all Dst for the six storms are reasonably represented by the lognormal form. The average of these positive storm correlation coefficients between Dst and the lognormal fitting was 0.91 (with a median value of 0.92 ). The 27 November storm stands out with a 0.99 correlation, resulting from the absence of irregularities in the form of the Dst index on that date.

The ap index is derived from the 3-hr range of field variation and therefore lacks an indication of the long-duration 


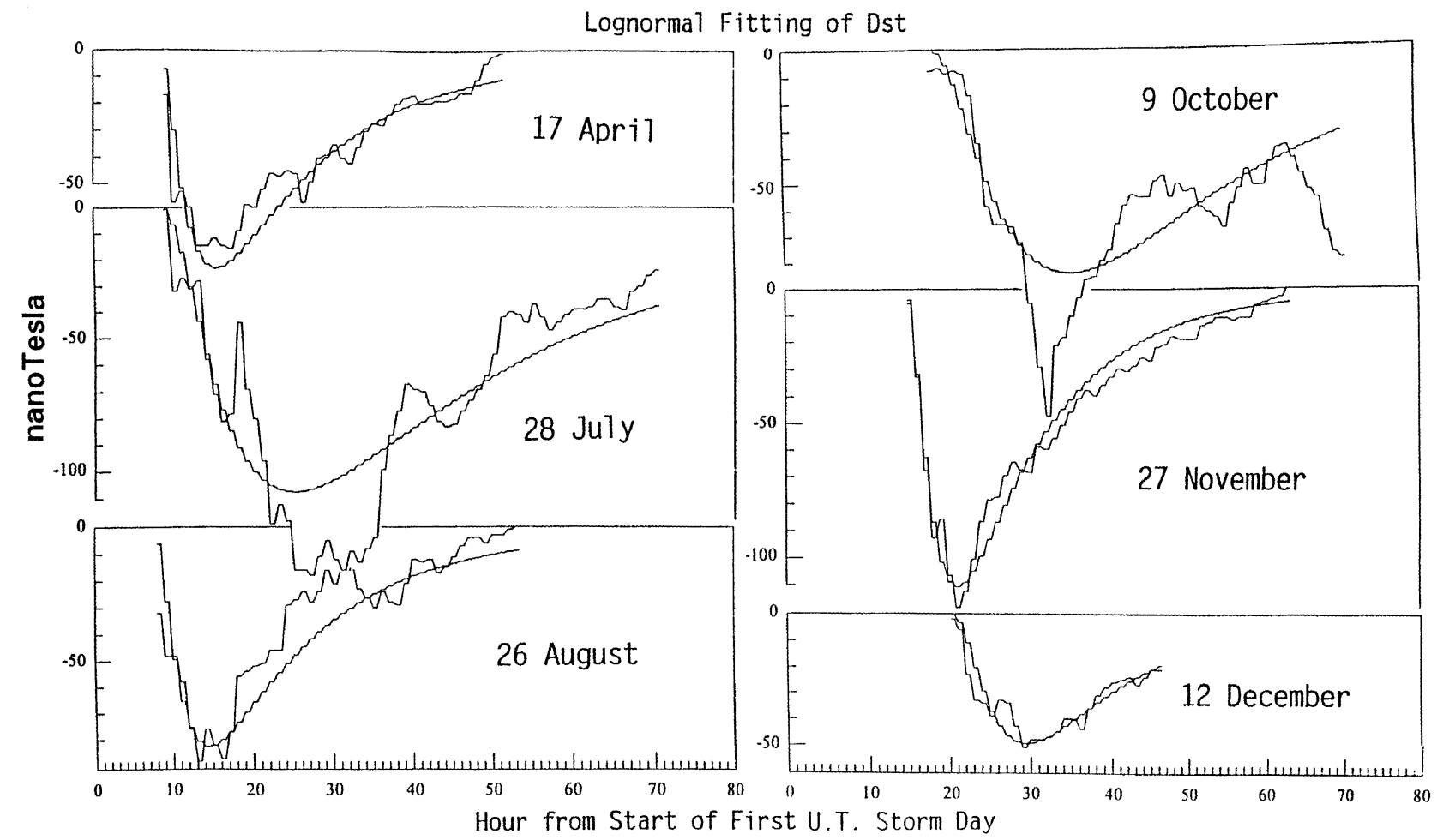

Fig. 6. Dst index and the lognormal distributions fit to the Dst for the six storms of this study.

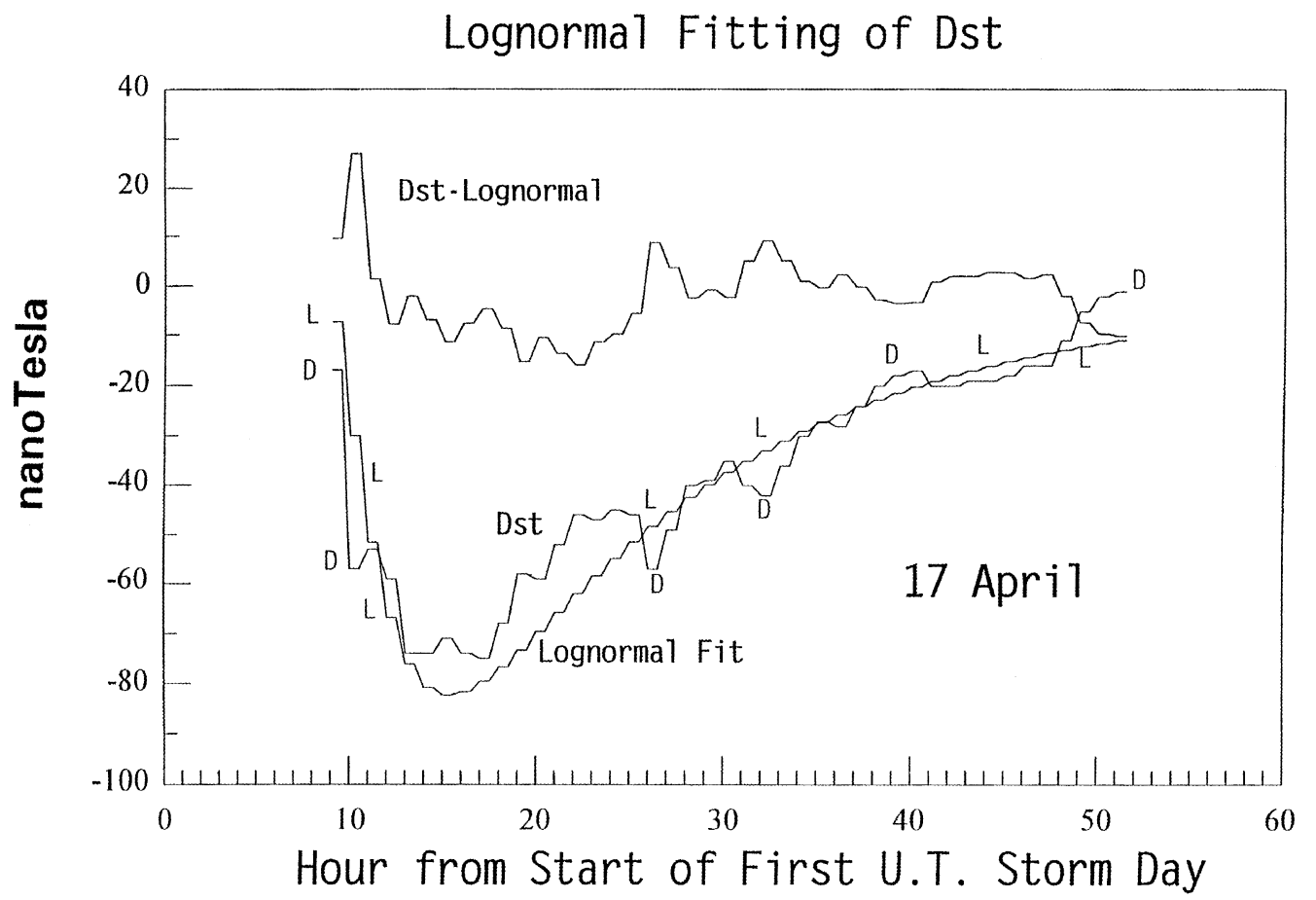

Fig. 7. The Dst index, lognormal fitting of Dst, and the difference between the two for the 17 April storm.

change seen in Dst. We wished to see whether the shortduration activity changes in Dst correspond to times of magnetic activity registered by the ap index. For that purpose, the smooth lognormal representation of Dst was subtracted from the Dst index (Fig. 7) and that difference was determined for each of the six storms for a comparison to the ap index. The resulting correlation coefficients showed that no consistent relationship existed. The coefficient values ranged from +0.69 to -0.38 to with a median value of -0.11 . This conclusion was similar to the earlier result showing that the ap index was an inconsistent indicator of the Australian magnetic activity.

In order to develop an indicator of Australian magnetic activity that can be derived rapidly from local data, an Aus- 
tralian variation of the Dst index was designed. This index (OZD) was created from the four standard observatories at Charters Towers, Learmonth, Gnangara, and Canberra processed in a way similar to that used for the formation of the Dst index from its contributing observatories. The average of the linear regression correlation coefficients between OZD and the Dst indices for all the storms was +0.91 and ranged from +0.85 to +0.94 . Thus, it seems that the OZD index may be usefully substituted for the Dst index without major difficulty.

\section{Lognormal Removal}

For many years following the declaration that the magnetic storm field at low latitudes, represented by Dst, was a true indication of the growth and decay of a magnetospheric ring current (Chapman, 1951) it was fashionable to subtract the Dst values from the magnetic fields at low and middle latitudes in order to obtain the "true" (non-magnetospheric) surface magnetic field values. This procedure continued until the analysis of the first satellite observations designed to sample the representative region (Lui et al., 1987), showed that the simple ring-current model for Dst was invalid.

The main and recovery phase of the storm-time Dst is usually not smooth but contains a number of small variations. As a result, the subtraction of Dst from the adjusted $\mathrm{H}$ (with baseline and $\mathrm{Sq}$ removed and corrected for latitude) introduces those variations into the computed difference when they were not in the local field originally. That fact degrades the significance of a linear regression correlation coefficient.

To determine whether the relationship between station fields (Table 3(a)) was dependent upon the similar appearance of the Dst form in the Australian magnetic records, the smooth lognormal fitting of Dst (Fig. 6) was subtracted from the storm magnetic records and the residuals also compared between stations. Only the main and recovery phases of the storms were considered here because of the limitations of the lognormal fitting of Dst. Table 3(b) shows the results. The high correlations between stations remained always positive and only slightly lower than those fields without the removal of lognormal Dst. Again, pairs of stations which were closest showed correlations of greater than 0.89 ; stations most widely separated had correlations between 0.74 and 0.83 . Because the lognormal Dst form did not dominate the correlations, the indication is that local measured field variations are extensively spread throughout the Australian continent. Therefore, the present distribution of magnetic observatories would suffice for indicators of continental magnetic activity in an aeromagnetic survey.

\section{Discussion}

The "planetary" ap index does indicate whether a day may be disturbed or quiet. However, for the individual geomagnetic storm days, there was such an inconsistent relationship between the actual Australian storm field records and the ap index (a linear form of the pseudo-logarithmic Kp index) that it was advisable to ignore those global index values as indicative of local magnetic activity variability. The problem undoubtedly arises because of the poor international distribution of Kp contributing stations - dominated by European locations and higher-latitude observatories (see figure
3.52 in Campbell, 2003). Also the Kp index is derived from the range of magnetic field activity in a 3-hr interval. This feature of $\mathrm{Kp}$ discriminates against slowly changing major departures of the field and, because magnetic field disturbance amplitudes usually increase with increasing period in our range of interest, the high-frequency portion of the disturbance spectra is essentially ignored in favor of the field variations close to the 3 -hr period portion. It is therefore believed that the ap (and $\mathrm{Kp}$ ) indices can only indicate the possibility (not the magnitude) of quiet or disturbed magnetic activity at global locations similar to Australia. Correlations between ap and Dst indices were also typically poor and negative, much similar to the ap versus local field relationships. That supported a previously understood fact that the two indices were of significantly different character.

The Dst index was compared to a local index, OZD, derived in a manner similar to the Dst, only using the four standard Australian observatories near the four corners of that continent (Fig. 1). The high correlation between OZD and Dst indicated that OZD index could be successfully used as an immediate local proxy for Dst. (A preliminary global Dst is available at website http://swdewww.kugi.kyotou.ac.jp/dstdir/dst1/quick.html)

Figure 6 supported the recent view (Campbell, 1996) that the Dst can be clearly represented by the negative of a lognormal distribution. Such a distribution becomes a normal form when plotted with the logarithm of the $\mathrm{x}$-axis. Normal distributions are symmetric about their maximum. Thus, the measured profile from the main phase start to the Dst minimum (the time of the change-over from the main to recovery phases of the Dst storm index-Fig. 2) determines the form and duration of the storm recovery time (cf. free computer program, DSTDEMO, in Campbell, 2003, pg 317). The importance of this feature may be recognized by radiowave and space disturbance forecasting centers (such as IPS in Australia) that desire to predict when a concurrent ionospheric distrubance (Wilkinson, 1995; Wu and Wilkinson, 1995; Yeh et al., 1992, 1994) can be expected to end, using just the realtime determination of the geomagnetic storm magnetic main phase.

Latitude and longitude extension of the magnetic features were investigated using the storm field correlations shown in Table 3(a). As expected, the closely located stations showed a high correlation of +0.97 . But even for the most distant stations the correlation dropped only to values between +0.90 and +0.93 . Thus, for our six storms of various months in 1990, similar magnetic variations seemed to be widespread throughout the Australian continent. The present distribution of Australian observatories should be sufficient for use in a continental aeromagnetic survey.

One-minute resolution of individual spikes on the 17 April storm indicated north-south simultaneity but both east-west and west-east delays in occurrence with apparent arrival differences ranging from 5 to $17 \mathrm{~km} / \mathrm{sec}$. Such great speed exceeded the expectation of a dynamo current responding to a thermospheric pressure wave that travels near sound velocity (Campbell and Young, 1963). Yet it must be recalled that magnetic fields from hydromagnetic wave propagation have been clocked at about $2,300 \mathrm{~km} / \mathrm{sec}$ (Campbell and Thornberry, 1972). A more definitive study of the apparent spike 
Table 5. Correlation coefficients for regression between Dst and the fitted lognormal distribution.

\begin{tabular}{cccccc}
\hline 17APR & 28JUL & 26AUG & 09OCT & 27NOV & 12DEC \\
\hline 0.94 & 0.90 & 0.92 & 0.78 & 0.99 & 0.93 \\
\hline
\end{tabular}

propagation time is needed because the possibility of a station clock-setting error could not be ruled out. If nothing else, the timing difference may be taken as a measure of the limitation in a determination of simultaneity for events in these data sets.

The Dst contains irregularities that are smoothed out in the formation of the lognormal fitting. Subtraction of the Dst just introduces these irregularities into the residual $\mathrm{H}$. To avoid this problem, the smooth lognormal representation of Dst (see Fig. 6) was subtracted from the corresponding storm field records at each station so that another and different correlation between stations could be performed. Table 3(b) indicated that the generalization regarding the widespread similarity of the storms remained. We consider these results to mean that a higher density of magnetic observatories through Australia is not required for monitoring the disturbed magnetic field conditions.

Recall that the lognormal form for the 27 November storm stood out with a correlation with Dst of +0.99 (Table 5). Assuming that the magnetic storm field effects create the lognormal form from a summation of the arrival of a multitude of normal field distributions (either in sequence or simultaneously), then the smoother the lognormal fitting in such a storm suggests a greater number of dominant contributing magnetic field events, none of outstanding size. If that is the case, then there would not be isolated and unrelated contributions at each geographic location; the field forms would all be similar, resulting in the observed high magnetic field correlation between all pairs of stations for the storm on this date.

Although this study is specific to the Australian continent, it would be reasonable to assume that locations of comparable latitude and longitude throughout the world would behave in a similar manner.
Acknowledgments. We give our thanks to the Geomagnetism Group of Geoscience Australia, the National Geophysical Data Center of NOAA, and the IPS Radio and Space Services of Australia for the free access to information used in this study and especially to the numerous workers in those organizations whose daily attention to data collection make their major contribution to scientific research.

\section{References}

Aitchison, J. and J. A. C. Brown, The Lognormal Distribution and Special Reference to Its Use in Economics, Cambridge Univ. Press, Cambridge, $176 \mathrm{pp}, 1957$.

Campbell, W. H., Geomagnetic storms, the Dst ring-current myth, and lognormal distributions, J. Atmos. Terr. Phys., 58, 1171-1187, 1996.

Campbell, W. H., Earth Magnetism, A Guided Tour Through Magnetic Fields, Harcourt Academic Press, San Diego, 151 pp, 2001.

Campbell, W. H., Introduction to Geomagnetic Fields, Second Edition, Cambridge University Press, Cambridge, 342 pp, 2003.

Campbell, W. H. and T. Thornberry, Propagation of Pc 1 hydromagnetic waves across North America, J. Geophys. Res., 77, 1941-1950, 1972.

Campbell, W. H. and J. Young, Auroral zone observations of infrasonic pressure waves related to ionospheric disturbances and geomagnetic activity, J. Geomag. Res., 68, 5909-5916, 1963.

Campbell, W. H., C. E. Barton, F. H. Chamalaun, and W. Welsh, Quiet-day ionospheric currents and their application to upper mantle conductivity in Australia, Earth Planets Space, 50, 347-360, 1998.

Chapman, S., The Earth's Magnetism, John Wiley, New York, 127 pp, 1951.

Jacobs, J. A. (ed.), Geomagnetism, vol. 4., Academic Press, New York, 806 pp, 1991.

Lui, A. T. Y., R. W. McEntire, and S. M. Krimigis, Evolution of the ring current during two geomagnetic storms, J. Geophys. Res., 92, 7459-7470, 1987.

Moos, N. A. F., Colaba Magnetic Data, 1846 to 1905, Indian Institute of Geomagnetism, Bombay, 782 pp, 1910.

Sugiura, M., Hourly values of the equatorial Dst for IGY, in Ann. Internat. Geophys. Year, vol. 35, p. 945, Pergamon Press, Oxford, 1964.

Wilkinson, P. J., Predictability of ionospheric variations for quiet and disturbed conditions, J. Atmos. Terr. Phys., 57, 1469-1481, 1995.

$\mathrm{Wu}, \mathrm{J}$. and P. J. Wilkinson, Time-weighted magnetic indices as predictors of ionospheric behavior, J. Atmos. Terr. Phys., 57, 1763-1770, 1995.

Yeh, K. C., K. H. Lin, and R. O. Conkright, The global behavior of the March 1989 ionospheric storm, Can. J. Phys., 70, 532-543, 1992.

Yeh, K. C., S. Y. Ma, and K. H. Lin, Global ionospheric effects of October 1989 geomagnetic storm, J. Geophys. Res., 99, 6201-6218, 1994.

W. H. Campbell (e-mail: Wally.Campbell@noaa.gov), C. E. Barton, P. Hopgood, and D. G. Cole 